\title{
La falta de legitimación de la Administración autonómica para instar la revisión de oficio de actos locales
}

\author{
Antonio Bueno Armijo \\ Profesor Titular de Derecho Administrativo \\ Universidad de Córdoba ${ }^{1}$
}

SUMARIO: I. INTRODUCGIÓN: LA DESCONGERTANTE FIGURA DE LA REVISIÓN DE OFICIO A SOLICITUD DE INTERESADO Y EL AÚN MÁS DESGONGERTANTE USO DE ESTA FIGURA POR LAS ADMINISTRACIONES SUPERIORES FRENTE A LA ADMINISTRAGIÓN LOGAL. II. EL PUNTO DE PARTIDA NORMATIVO: EL RÉGIMEN DE IMPUGNACIÓN DE LOS ACTOS LOCALES RECOGIDO EN EL ART. 65 LRBRL Y LA TENTAGIÓN DEL ART. 106.1 LPAC. III. UNA EXTRAORDINARIA HISTORIA DE CONFUSIONES Y MALENTENDIDOS: LOS PRONUNCIAMIENTOS DE LOS TRIBUNALES SUPERIORES DE JUSTICIA FAVORABLES A ADMITIR LA LEGITIMAGIÓN AUTONÓMICA PARA SOLICITAR LA REVISIÓN DE OFICIO. IV. EL PRIMER AGERGAMIENTO DEL TRIBUNAL SUPREMO A LA MATERIA, EN EL QUE AMAGA, PERO NO DA, Y COMPLICA INNECESARIAMENTE EL DEBATE. V. LA INESPERADA APARICIÓN DEL TRIBUNAL SUPERIOR DE JUSTICIA DE ANDALUCÍA/GRANADA Y SU NEGATIVA A ACEPTAR LA LEGITIMACIÓN GENERAL DE LA ADMINISTRAGIÓN AUTONÓMICA PARA SOLICITAR LA REVISIÓN DE OFICIO. VI. EL DEFINITIVO RECHAZO DEL TRIBUNAL SUPREMO A LA LEGITIMAGIÓN DE LA ADMINISTRACIÓN AUTONÓMICA PARA SOLICITAR LA REVISIÓN DE OFICIO. VI. GONCLUSIÓN: LA DEGRADACIÓN DE LA ADMINISTRACIÓN AUTONÓMICA A LA POSICIÓN DE MERA DENUNCIANTE Y SUS NADA DESDEÑABLES CONSECUENCIAS

Grupo de Investigación de la Junta de Andalucía SEJ-196. Proyecto DER2015-67695-C2-1-P (MINECO FEDER UE). 
RESUMEN: El ordenamiento jurídico atribuye a la Administración del Estado y de las Comunidades Autónomas la potestad de impugnar judicialmente cualquier acto o acuerdo adoptado por las Administraciones locales (art. 65 LRBRL). Sin embargo, dicha impugnación solo puede hacerse dentro de los breves plazos marcados por la Ley. Por este motivo, algunas Comunidades Autónomas han optado por solicitar a las Administraciones locales la revisión de oficio de sus actos, aprovechando la ausencia de plazo para ello (art. 106.1 LPAG). Estos intentos han dado lugar a un intenso debate jurídico acerca de cuáles son los requisitos que deben cumplir las Comunidades Autónomas para que sus solicitudes de revisión deban ser obligatoriamente atendidas por las Administraciones locales. Tras una larga controversia, el Tribunal Supremo ha concluido que las Administraciones locales sólo están obligadas a iniciar sus procedimientos de revisión de oficio en caso de que las Comunidades Autónomas ostenten un interés legítimo.

PALABRAS CLAVE: Actos administrativos inválidos; revisión de oficio; interés legítmo.

ABSTRACT: The Spanish legal order has granted the State's and the Autonomous Communities' Administrations the power to bring an action before the Courts against any administrative act adopted by Local Governments (art. 65 LRBRL). However this action must be filed within short deadlines. This is why some Autonomous Communities had tried to force Local Governments to open ex officio reviews against their own administrative acts, given that this kind of review can be undertaken at any time (art. 106.1 LPAG). These attempts had caused a legal controversy about which are the requirements that must be met by the Autonomous Communities to make their requests compulsory for the Local Governments. After a long debate, the Spanish Supreme Court has ruled out that Local Governments are bound to initiate an ex officio review if, and only if, the Autonomous Communities show a legitimate interest.

KEY WORDS: Illegal administrative act; ex officio review; legitimate interest.

I. INTRODUCGIÓN: LA DESGONGERTANTE FIGURA DE LA REVISIÓN DE OFICIO A SOLICITUD DE INTERESADO Y EL AÚN MÁS DESCONCERTANTE USO DE ESTA FIGURA POR LAS ADMINISTRAGIONES SUPERIORES FRENTE A LA ADMINISTRACIÓN LOCAL

El art. 106.1 de la Ley 39/2015, de 1 de octubre, de Procedimiento Administrativo Común de las Administraciones Públicas (en adelante, LPAC) -como antes que él el art. 102.1 LRJPAC- es claro al consagrar la revisión de oficio de los actos 
administrativos: «Las Administraciones Públicas (...) por iniciativa propia o a solicitud de interesado (...) declararán de oficio la nulidad de los actos administrativos (...)»². La doctrina no ha dejado de destacar la paradoja de que una revisión «de oficio» pueda ejercerse no solo de oficio, sino «a solicitud de interesado», lo que da lugar, sin ningún género de dudas, a una de las figuras más contradictorias de nuestro Derecho.

Esta contradictio in terminis, de hecho, solo resultaría explicable por situaciones pasadas de nuestro Derecho positivo, ampliamente superadas hace ya décadas ${ }^{3}$. O, en

2 En relación con el nuevo régimen jurídico de la revisión de oficio contenido en los arts. 106-110 LPAC, vid., con carácter general, Antonio Bueno Armijo, «La revisión de oficio», en Humberto Gosálbez Pequeño (dir.), La nueva Ley del Procedimiento Administrativo Común, Wolters-Kluwer, Madrid, 2016, pp. 371 450. Dado que la nueva regulación prácticamente ha dejado intacta la anterior, contenida en los arts. 102 a 106 LRJPAC, resulta igualmente de utilidad la consulta de las obras referidas a estos artículos. Entre otras, cabe destacar: Jerónimo Arozamena Sierra, «Comentario al capítulo primero del título VII de la Ley 30/1992, de 26 de noviembre (arts. 102 al 106). Revisión de oficio de actos y disposiciones reglamentarias», Revista de Administración Pública, no 140 (mayo - agosto 1996), pp. 69-93; Raúl Bocanegra Sierra, Lecciones sobre el acto administrativo, Civitas, Cizur Menor, $4^{\mathrm{a}}$ edición, 2012; Faustino Cordón Moreno, La revisión de oficio de los actos administrativos y disposiciones de carácter general y su control jurisdiccional. Un estudio desde la jurisprudencia, Thomson-Civitas, Cizur Menor, 2013; Montserrat Cuchillo Foix, «La revisión de oficio y la revocación en la LRJPAC», en Joaquín TORnOs MAS (coord.), Administración pública y procedimiento administrativo: comentarios a la Ley 30/1992, de 26 de noviembre, Bosch, Barcelona, 1994, pp. 347-428; Ángeles De PALma DEL Teso, «La acción de nulidad frente a los actos desfavorables o de gravamen», RAP n 159 (septiembre - diciembre 2002), pp. 401-416; José Garberí Llobregat y Guadalupe Buttrón Ramírez, «Revisión de actos en vía administrativa. Revisión de oficio», en José GARBErí Llobregat (coord.), El procedimiento administrativo común (comentarios, jurisprudencia, formularios), Tirant lo Blanch, Valencia, 2007, vol. II, pp. 1821-1960; José Antonio García-Trevijano Garnica, «Capítulo 13. Revisión de oficio de actos administrativos», en Benigno PenDÁs (coord.) Administraciones públicas y ciudadanos, Praxis, Barcelona, 1993, pp. 631-700; Fernando GARRIDO Falla y José María Fernández Pastrana, Régimen jurídico y procedimiento de las Administraciones públicas, Civitas, Madrid, $2^{a}$ ed., 1995; Rafael Gómez-Ferrer Morant, «Capítulo XI. La revisión de oficio», en Jesús Leguina Villa y Miguel Sánchez Morón (dirs.), La nueva Ley de Régimen jurídico de las Administraciones públicas y del procedimiento administrativo común, Tecnos, Madrid, 1993, pp. 282-320; Jesús GonzÁLez Pérez, y Francisco González Navarro, «Revisión de oficio», Comentario a la Ley de Régimen furídico de las Administraciones públicas y procedimiento administrativo común (Ley 30/1992, de 26 de noviembre), Civitas, Madrid, $2^{\text {a }}$ edición, 1999, pp. 2211-2280; José Ramón PARAda VÁzQuez, Régimen jurídico de las Administraciones públicas y procedimiento administrativo común. Estudio, comentarios y texto de la Ley 30/1992, de 26 de noviembre, Marcial Pons, Madrid, 1993, pp. 339-357; Beatriz Rodríguez Villar, «Artículo 102», en Miguel SÁnchez Morón y Nicolás Maurendi Guillén (eds.), Comentarios a la Ley 30/92, Lex Nova - Thomson, Valladolid, 2013, pp. 631-639; José Manuel SAla Arquer, «La revisión de oficio de los actos administrativos» en Juan Carlos Fernández de Aguirre (dir.), Cuadernos de Derecho Fudicial. n 18. Valoración de la Ley 30/1992 tras cinco años de vigencia, Madrid, 1997, pp. 289-304; José SuAY Rincón, «La caracterización jurídica de la potestad de revisión de oficio (Un análisis de Derecho positivo de esta institución)» en José Eugenio Soriano García (dir.), Por el derecho y la libertad. Libro Homenaje al Profesor Fuan Alfonso Santamaria Pastor, Iustel, Madrid, 2014, vol. II, pp. 1355-1408; Antonio ZAFRA Jiménez, «Los recursos administrativos y los procedimientos de revisión», en Pascual SALA SÁnchez, Juan Antonio Xiol Ríos y Rafael Fernández Montalvo (dirs.), Las instituciones del Derecho Administrativo en la jurisprudencia, Tomo II, Bosch, Barcelona, 2011, pp. 1483-1599.

3 En efecto, lo que originariamente se pretendió con el reconocimiento de la revisión de oficio a solicitud de interesado fue completar las escasas posibilidades que ofrecían a los ciudadanos los recursos en 
el mejor de los casos, por algunas interpretaciones extremas de la teoría de la nulidad, cuyos perturbadores efectos para nuestro ordenamiento permiten comprender el claro rechazo que este ha mostrado frente a ellas ${ }^{4}$.

El resultado de tan paradójica figura es una operación materialmente indistinguible de los recursos administrativos, con los que comparte idéntica finalidad: obligar a la Administración a revisar por sí misma sus propios actos por motivos de legalidad y obligarla igualmente, en caso de que determine la concurrencia de una causa de nulidad, a declarar también por sí misma su invalidez, salvo que concurran ciertos límites. Se trata, por tanto, de una verdadera «acción de nulidad» reconocida a los ciudadanos, consagrada con toda claridad por el legislador (cfr. art 125.3 LPAG) y plenamente tutelable por los jueces y tribunales.

vía administrativa para combatir los actos administrativos que reputaban ilegales. Como tempranamente expuso Miguel Sánchez MoRón, «La revisión de oficio», en Fornadas de Estudio sobre la Reforma de la Ley 30/1992: Fornadas celebradas en Sevilla los días 23 y 24 de febrero de 1997, Ministerio de Administraciones Públicas - BOE, Madrid, 1997, pp. 144-145, los recursos administrativos regulados en la Ley de Procedimiento Administrativo de 1958 (LPA) resultaban tan limitados (v. gr., solo se concedían quince días para interponer alzada), que se forzó la interpretación del art. 109 LPA (que no hablaba de «a solicitud de interesado», sino de «a instancia de interesado») para dotar a los administrados de una posibilidad de recurso en vía administrativa más amplia, bajo la forma de «revisión de oficio a solicitud de interesado». De este modo, se desnaturalizó consciente y deliberadamente la revisión de oficio para obligarla a acoger, también, una suerte de recurso administrativo encubierto. La LRJPAC y su reforma de 1999 construyeron un sistema de recursos en vía administrativa criticable, pero suficientemente garantista, que hacía innecesario el mantenimiento de la revisión de oficio a solicitud de interesado. Sin embargo, esta se mantuvo. Y lo mismo hace ahora la LPAC.

4 Para algún autor, la gravedad de los vicios que dan lugar a la nulidad de pleno Derecho y la extraordinaria afectación al ordenamiento que suponen justificaría que cualquier ciudadano pudiera ejercer la acción de nulidad. En efecto, la afirmación sin matices de que las consecuencias de la nulidad de pleno derecho son la ausencia total y absoluta de efectos del acto llevaría necesariamente a admitir que cualquier ciudadano podría actuar contra él, lo que implicaría el reconocimiento de una acción pública para todos los supuestos de nulidad de pleno derecho. Así lo ha considerado, notoriamente, Bocanegra Sierra, Raúl (2012), 214-215, y lo han advertido otros autores, como CuchilLo Foix, Montserrat (1994), 371-372. Frente a ello, sin embargo, el art. 106.1 LPAC emplea deliberadamente la expresión «a solicitud de interesado», lo que debe identificarse con alguno de los sujetos a los que se refiere el artículo 4 LPAC: los titulares de derechos subjetivos o intereses legítimos afectados por el acto impugnado, pero no quienes ostenten un simple interés. Se comprenden, por otra parte, la cautela del legislador y el saludable límite que impone a los excesos que esa interpretación extrema de la teoría de la nulidad conllevaría. Así es, la declaración de nulidad puede acarrear consecuencias negativas para otros administrados distintos del actuante y el ordenamiento debe tomar precauciones para que instrumentos como este no se utilicen para dar cauce a ataques de un ciudadano sobre otro sin más objeto que lograr satisfacción con el mal causado. De ahí la necesidad de que concurra una legitimación basada en la existencia de un derecho subjetivo o un interés legítimo. En ese sentido, Manuel Rebollo Puig, «La nulidad en Derecho Administrativo: consideración de su significado y régimen en el actual Derecho Administrativo español a propósito de la nulidad por vulneración de los derechos fundamentales», Fusticia Administrativa n ${ }^{\circ} 44,2009$, p. 26, recuerda que la teoría clásica de la nulidad nunca llegó al extremo de afirmar que no hace falta ninguna legitimación para invocar con éxito la nulidad. Todo ello, sin perjuicio de lo que más adelante se dirá en texto en relación con la categoría de "acto inexistente" o con los supuestos de acción popular. 
Tan extraña figura alcanza, sin embargo, sus máximas cotas de singularidad cuando la revisión de oficio a solicitud de interesado es ejercida, no por un ciudadano, sino por una Administración pública distinta a la Administración autora del acto. Ciertamente, y como se verá, una interpretación literal del art. 106.1 LPAC no permite excluir la posibilidad de que una Administración pública pueda solicitar la revisión de oficio de un acto nulo de pleno derecho a otra Administración pública distinta y autora del acto. Sin embargo, para que resulte admisible deben cumplirse, al menos, dos requisitos:

- en primer lugar, debe reunirse la condición de «interesado» exigida por el art.106.1 LPAC e interpretada de conformidad con el art. 4 LPAC;

- en segundo lugar, no puede constituirse en una vía alternativa a otros mecanismos de control de la legalidad de la actuación de unas Administraciones públicas sobre otras y, muy especialmente, al mecanismo del art. $65 \mathrm{LRBRL}^{5}$.

A despecho de estas prevenciones, durante los últimos años la Junta de Andalucía ha venido realizando un uso muy intenso y, podría pensarse, casi abusivo de la revisión de oficio a solicitud de interesado del art. 106.1 LPAC, ejerciendo de manera continuada la acción de nulidad contenida en este artículo contra los actos de las Entidades locales andaluzas que reputaba nulos, aun sin gozar de la condición de «interesada». Esta situación, denunciada en varias ocasiones por Manuel Rebollo PuIG $^{6}$, ha dado como resultado una interesante confrontación jurídica entre la Junta de Andalucía, apoyada en la jurisprudencia elaborada por varios Tribunales Superiores de Justicia, incluyendo el de Andalucía, sede de Málaga, por un lado, y la Sala de lo Contencioso-Administrativo del Tribunal Superior de Justicia de Andalucía, sede de Granada, por el otro, pues esta última ha rechazado sistemáticamente la consideración de la Junta de Andalucía como interesada a efectos del art. 106.1 LPAG. La disputa ha sido finalmente resuelta por la STS de 12 de abril de 2016, recurso de casación no 3550/2014 (ponente: De Oro-Pulido López), a favor de las tesis de la Sede de Granada del Tribunal andaluz.

El objeto del presente trabajo es, justamente, revisar las fases por las que ha pasado esta controversia y exponer los motivos por los que la Administración autonómica

\footnotetext{
Bueno Armijo, Antonio (2016):380, 393.

Manuel Rebollo Puig, «Revisión de oficio de los acuerdos locales a instancia de las Administraciones estatal y autonómicas», en Alberto RUIZ OJEDA (coord.) El gobierno local. Estudios en homenaje al profesor Luis Morell Ocaña, Iustel, Madrid, 2010, pp. 453-482, y Manuel Rebollo Puig, «Legitimación de las administraciones autonómicas para instar la revisión de oficio de los acuerdos municipales (Comentario a la sentencia del Tribunal Supremo de 29 de septiembre de 2010)», en Eduardo García de EnTERría y Ricardo Alonso García (coords.), Administración y Justicia: un análisis jurisprudencial. Liber amicorum Tomás-Ramón Fernández, Civitas, Madrid, 2012, Vol. I, pp. 2019-2034.
} 
no puede instar la revisión de oficio de los acuerdos municipales por la vía del art. 106.1 LPAC más que en casos excepcionales.

\section{EL PUNTO DE PARTIDA NORMATIVO: EL RÉGIMEN DE IM- PUGNAGIÓN DE LOS ACTOS LOGALES REGOGIDO EN EL ART. 65 LRBRL Y LA TENTACIÓN DEL ART. 106.1 LPAC}

El ordenamiento español ha establecido como una de las manifestaciones de la tutela administrativa ejercida sobre las Entidades locales por parte de la Administración del Estado y de las Comunidades Autónomas la del control de legalidad sobre actos concretos de aquellas. El art. 65 LRBRL permite a ambas Administraciones superiores, en el plazo de quince días hábiles desde que les sea comunicado, requerir a la Entidad local autora de un acto o acuerdo que consideren contrarios al ordenamiento jurídico para que, dentro del mes siguiente, lo anulen. Si el requerimiento no fuera atendido, la Administración requirente podrá impugnar el acto o acuerdo ante la jurisdicción contencioso-administrativa en el plazo ordinario de dos meses. De manera alternativa a lo anterior, ambas Administraciones superiores pueden también impugnar el acto o acuerdo directamente ante la jurisdicción contencioso-administrativa, sin necesidad de requerimiento previo, ajustándose nuevamente al plazo ordinario de dos meses.

El requerimiento previo a la impugnación, aunque potestativo, supone abrir a las Entidades locales una vía nueva y autónoma para la revisión de sus actos ilegales, tal y como se deduce del art. $53 \mathrm{LRBRL}^{7}$. De este modo, el único trámite que debe evacuarse antes de proceder, en su caso, a la anulación del acto objeto del requerimiento es la audiencia al interesado (art. 215.3 ROF).

Sin embargo, este precepto no concede ni a la Administración del Estado ni a las de las Comunidades Autónomas una auténtica potestad de control sobre las Entidades locales. En realidad, la única ventaja que les atribuye, aunque de grandísima importancia, es de carácter procesal ${ }^{8}$. En efecto, este artículo reconoce a las Administraciones superiores una legitimación general para impugnar los actos o acuerdos de

\footnotetext{
De acuerdo con el tenor literal del art. 53 LRBRL: «Sin perjuicio de las previsiones específicas contenidas en los artículos 65, 67 y 110 de esta Ley, las Corporaciones locales podrán revisar sus actos y acuerdos en los términos y con el alcance que, para la Administración del Estado, se establece en la legislación del Estado reguladora del procedimiento administrativo común». De este modo, el legislador distingue claramente la revisión de los actos y acuerdos que las Entidades locales pueden hacer a resultas del requerimiento regulado en el art. 65.1 LRBRL y la revisión de oficio recogida en los arts. 106 - 110 LPAC.

8 Así lo reconoció, tempranamente, la STC 214/1989, de 21 de diciembre, afirmando que «los arts. 65 y 66 LRBRL presentan una incuestionable dimensión jurídico-procesal (...). No se trata, en realidad, de un control de los actos y acuerdos locales por la Administración estatal o autonómica, sino de la
} 
las Entidades locales ante los órganos de lo contencioso-administrativo, sin necesidad de probar la afectación de un derecho subjetivo o interés legítimo sino, sencillamente, por reputarlos contrarios al ordenamiento jurídico ${ }^{9}$. Esta privilegiada situación se confirma, además, en otros preceptos del ordenamiento, tanto en materia de régimen local ${ }^{10}$ como en materia procesal ${ }^{11}$. En contrapartida, eso sí, el art. 65 LRBRL recuerda insistentemente la existencia de un plazo preclusivo para poder interponer recurso contencioso-administrativo por parte de tales Administraciones.

$\mathrm{Al}$ margen de las dos vías previstas en este artículo, y de lo establecido en los sucesivos arts. 66 y 67 para otros supuestos distintos ${ }^{12}$, la Administración del Estado y de las Comunidades Autónomas no disponen de más mecanismos para atacar los actos y acuerdos de las Entidades locales que estimen ilegales. En consecuencia, agotados los plazos a los que hace referencia el art. $65 \mathrm{LRBRL}$ sin que aquellas hayan llegado a interponer recurso contencioso-administrativo, los actos o acuerdos de estas devienen inatacables.

La situación no es muy diferente a la de cualquier administrado que deja que se agoten los plazos para interponer un recurso contencioso-administrativo contra un acto que le afecta, sin llegar a presentarlo nunca. Sin embargo, es precisamente en

regulación de la legitimación precisa para la impugnación de los mismos ante la jurisdicción contencioso-administrativa».

9 En rigor, el art. 65 LRBRL exige que el control de legalidad de la Administración del Estado y de las Comunidades Autónomas se produzca «en el ámbito de las respectivas competencias». Sin embargo, la jurisprudencia ha hecho una interpretación muy flexible y claramente pro actione de lo que debe entenderse incluido en dicho ámbito, tanto a favor de la Administración del Estado como de la Administración de las Comunidades Autónomas. El resultado es que se ha acabado reconociendo a estas Administraciones, de hecho, una legitimación general para impugnar cualquier acto o acuerdo de las Entidades locales por motivos de legalidad, tal y como explica Eloísa Carbonell Porras, «Artículo 65», en Manuel Rebollo Puig (dir.) y Manuel IzQuierdo Carrasco (coord.), Comentarios a la Ley Reguladora de las Bases del Régimen Local, Tomo II, Tirant lo Blanch, Valencia, 2007, en especial, pp. 1557-1564, con abundancia de citas jurisprudenciales.

10 Por un lado, el art. 63.1.a) LRBRL dispone que «Junto a los sujetos legitimados en el régimen general del proceso contencioso-administrativo podrán impugnar los actos y acuerdos de las Entidades locales que incurran en infracción del ordenamiento jurídico: a) La Administración del Estado y de las Comunidades Autónomas, en los casos y términos previstos en este Capítulo». Por su parte, el art. 214.1 ROF señala que «La Administración del Estado y las Comunidades Autónomas, en el ámbito de sus respectivas competencias, están legitimadas para impugnar los actos y acuerdos de las entidades locales que incurran en infracción del ordenamiento jurídico, en los casos y en los términos previstos en el artículo 65 de la Ley $7 / 1985$, de 2 de abril».

11 Los arts. 19.1.c) y d) LJCA atribuyen legitimación a la Administración del Estado y a la Administración de las Comunidades Autónomas para impugnar los actos y disposiciones de las Entidades locales «de conformidad con lo dispuesto en la legislación de régimen local».

12 En relación con el alcance de ambos artículos y su delimitación respecto al supuesto contemplado en el art. 65 LRBRL, vid. los exhaustivos análisis de Eloísa Garbonell Porras, «Artículo 66» y «Artículo 67» en Manuel Rebollo Puig (dir.) y Manuel Izquierdo Carrasco (coord.), Comentarios a la Ley Reguladora de las Bases del Régimen Local, cit., pp. 1577-1591 y 1593-1607. 
estos supuestos en los que puede operar el art. 106 LPAC, de conformidad con el cual el administrado podría solicitar de la Administración la revisión de oficio de los actos que no hubieran sido recurridos en plazo cuando se encontrasen viciados de nulidad de pleno derecho.

Tal y como se indicó más atrás, y frente a lo sostenido en épocas anteriores, la solicitud de revisión de oficio no es una mera petición que dirige el administrado a la Administración autora del acto, sino una verdadera «acción de nulidad» plenamente tutelable por los jueces y tribunales. Es decir, el ordenamiento jurídico reconoce el derecho de los administrados a que la Administración autora del acto admita, tramite y resuelva, en el sentido que corresponda, su solicitud de revisión ${ }^{13}$. Como es fácilmente comprensible, la Administración del Estado o de las Comunidades Autónomas pueden estar tentadas de acudir a la vía del art. 106 LPAC cuando también ellas hayan dejado correr los plazos para impugnar los actos de las Entidades locales.

Ahora bien, como también se indicó más atrás, la acción de nulidad consagrada en el art. 106.1 LPAC no se reconoce a todos los administrados, sino, más limitadamente, a quienes ostenten un derecho subjetivo o un interés legítimo. La dicción del art. 106.1 LPCAP no admite dudas al respecto, por cuanto se refiere expresamente a la revisión de oficio «a solicitud de interesado», lo que remite a los titulares de derechos subjetivos o intereses legítimos afectados por el acto impugnado, de conformidad con lo previsto en el art. 4 LPAC, pero no a quienes ostenten un simple interés.

Las únicas excepciones vendrían determinadas, quizá, por la categoría de acto inexistente (aunque en estos supuestos ni siquiera sería necesaria la revisión de oficio, pudiendo ser tales actos desconocidos, sin más) y por los supuestos de acción popu$\operatorname{lar}^{14}$, si bien en este último caso también podrían existir restricciones ${ }^{15}$. En todos los demás supuestos, sería necesario contar con un derecho subjetivo o un interés legítimo

13 De este modo, contra la resolución de inadmisión (o contra la falta de resolución) cabrá recurso, tanto en vía administrativa (art. 112.1 LPAC) como en vía contencioso-administrativa (art. 25.1 LJCA). En relación con el alcance del control judicial en estos casos y el posible contenido de la resolución que ponga fin al proceso judicial, Bueno Armijo, Antonio (2016): 395-396.

14 Así ocurriría, por ejemplo, con la acción pública en materia de costas, patrimonio histórico o urbanismo, esta última consagrada actualmente en el art. 62.1 del Texto Refundido de la Ley del Suelo y Rehabilitación Urbana (Real Decreto Legislativo 7/2015, de 30 de octubre): «Será pública la acción para exigir ante los órganos administrativos y los Tribunales Contencioso-Administrativos la observancia de la legislación y demás instrumentos de ordenación territorial y urbanística».

15 Cordón Moreno, Faustino (2013): 98, recuerda que el Dictamen del Consejo de Estado $\mathrm{n}^{\circ}$ 2124/1994, de 7 de diciembre, negó que la acción popular atribuyera la legitimación suficiente para solicitar la revisión de oficio. Asimismo, los tribunales niegan que las Administraciones de control puedan ejercer la acción popular contra los actos locales dictados en sectores en los que dicha acción existe, dado que entienden que, para estos supuestos, las Administraciones deben acudir al mecanismo del art. 65 LRBRL. Rebollo Puig, Manuel (2010): 477; Carbonell Porras, Eloísa (2007): 1568; María Dolores Rego Blanco, 
afectados, sin que resulte suficiente el simple interés en la revisión. Y esta exigencia resulta predicable tanto cuando el solicitante es un ciudadano como cuando el solicitante es otra Administración pública. Incluso cuando sea una Administración de control la que solicite la revisión de oficio a la Administración tutelada.

Sentado lo anterior, importa destacar ya algunas diferencias esenciales entre el art. 65 LRBRL y el art. 106.1 LPAC. El art. 65 LRBRL no exige que el acto de la Entidad local impugnado sea nulo de pleno derecho ni que afecte a un interés legítimo o derecho subjetivo de la Administración impugnante, pero sí somete el ejercicio de la acción a los plazos marcados por el propio art. 65 LRBRL y la LJCA. Casi de manera inversa, el art. 106.1 LPAC sí exige que el acto de la Entidad local impugnado sea nulo de pleno derecho y que afecte a un interés legítimo o derecho subjetivo de la Administración impugnante, pero no somete a plazo alguno el ejercicio de la acción de nulidad, que podrá utilizarse «en cualquier momento». Lo que el ordenamiento jurídico no ha previsto, de ningún modo, es la posibilidad de que las Administraciones del Estado o de las Comunidades Autónomas gocen, al mismo tiempo, de legitimación general para impugnar cualquier acto de las Entidades locales y de un plazo ilimitado de tiempo para proceder a dicha impugnación.

Sin embargo, esta última ha sido, justamente, la pretensión de la Junta de Andalucía en un amplísimo número de casos. No se trata, desde luego, de la única Administración autonómica que ha utilizado esta vía ${ }^{16}$. Sin embargo, su situación no tiene parangón: a partir de un simple repaso a la jurisprudencia que esta conducta ha generado, se colige la pasmosa habitualidad con que la Junta de Andalucía ha ejercido la acción de nulidad del art. 106.1 LPAC contra actos (y, en ocasiones, incluso disposiciones) de las Entidades locales andaluzas, sin contar más que con un simple interés en la legalidad de tales actuaciones y tras haber dejado expirar, sobradamente, los plazos para dirigirles el requerimiento al que hace referencia el art. 65.1 LRBRL o para interponer el correspondiente recurso contencioso-administrativo ante los órganos judiciales competentes ${ }^{17}$.

La acción popular en el Derecho Administrativo y, en especial, en el Urbanístico, Instituto Andaluz de Administración Pública, Sevilla, 2005, p. 212.

16 Aunque no muy frecuentes, es posible rastrear en la jurisprudencia reciente supuestos similares en otras Comunidades Autónomas, fundamentalmente en Cataluña [STSJ de Cataluña de 26 de septiembre de 2014 (recurso n ${ }^{\circ}$ 129/2013), Ayuntamiento de El Perelló] y Galicia [STSJ de Galicia de 14 de noviembre de 2013 (recurso n $^{\circ}$ 4342/2013), Ayuntamiento de Barreiros; STSJ de Galicia de 12 de febrero de 2015 (recurso n $^{\circ} 4461 / 2013$ ), Concello de Fisterra].

17 En las sentencias dictadas solo en los dos últimos años por el Tribunal de Justicia de Andalucía es posible encontrar noticia de alrededor de treinta solicitudes de revisión de oficio de acuerdos municipales (generalmente de concesión de licencias de obras o de primera ocupación) presentadas cuando ya habían pasado hasta tres y cuatro años de su adopción y dirigidas, entre otros, a los Ayuntamientos de Cómpeta [STSJ de Andalucía/Málaga de 14 de octubre de 2014 (recurso nº 692/201 1)], Nívar [STJS de Andalucía/ 


\section{UNA EXTRAORDINARIA HISTORIA DE CONFUSIONES Y MALENTENDIDOS: LOS PRONUNCIAMIENTOS DE LOS TRIBUNALES SUPERIORES DE JUSTICIA FAVORABLES A ADMITIR LA LEGITIMACIÓN AUTONÓMICA PARA SOLICI- TAR LA REVISIÓN DE OFICIO}

Hasta el año 2010, momento en el que se produce el primer pronunciamiento del Tribunal Supremo sobre la cuestión, el principal debate sobre si las Administraciones autonómicas podían acudir a la vía del art. 102.1 LRJPAC (actual art. 106 LPAG) para solicitar la revisión de oficio de los actos dictados por las Entidades locales se sustanció ante los Tribunales Superiores de Justicia. A lo largo de una década, estos elaboraron una jurisprudencia constante y homogénea, centrada en el ámbito urbanístico y favorable a las pretensiones de la Administración autonómica.

Salvo error, la primera sentencia que afirmó la legitimación de la Administración de una Comunidad Autónoma para instar la revisión de oficio de oficio del acuerdo adoptado por una Entidad local fue la STSJ de Cataluña de 25 de octubre de 2001 (recurso n ${ }^{\circ}$ 137/2001). En los hechos, la Generalidad de Cataluña había solicitado al Ayuntamiento de Sant Pere de Torelló la revisión de oficio de una licencia, dictada más de un año antes, que autorizaba la construcción de una nave de uso forestal. Ante la inactividad del Ayuntamiento autor del acto por más de tres meses, la Generalidad entendió que se había producido el silencio administrativo negativo y procedió a impugnarlo en vía contencioso-administrativa. El Juzgado de lo contencioso-administrativo que conoció del recurso en primera instancia decidió su inadmisión por extemporáneo, al entender que la Administración autonómica no podía instar la revisión de oficio y que la solicitud que había dirigido al Ayuntamiento debía entenderse que constituía el requerimiento potestativo al que hace referencia el art. 65.1 LRBRL. En consecuencia, el plazo de dos meses para interponer recurso contencioso-administra-

Granada de 16 de febrero de 2015 (recurso n ${ }^{\circ}$ 2064/2008)], Almuñécar [SSTJS de Andalucía/Granada de 17 de noviembre de 2014, 2 de febrero, 1 de junio, 20 de julio y 26 de octubre de 2015 y 26 de febrero de 2016 (recursos n ${ }^{\circ}$ 2068/2008, 1054/2008, 1467/2010, 213/2013, 599/2012 y 56/2015)], Roquetas de Mar [STJS de Andalucía/Granada de 22 de junio de 2015 (recurso n ${ }^{\circ} 697 / 2013$ )], Zurgena [SSTJS de Andalucía/Granada de 9 de marzo y 4 de mayo de 2015 (recursos n 79/2010 y 249/2012)], Cuevas de Almanzora [STJS de Andalucía/Granada de 9 de febrero y de 6 de abril de 2015 (recursos n ${ }^{\circ}$ 1814/2008 y 1407/2010)], Partaloa [STJS de Andalucía/Granada de 20 de octubre de 2014 (recurso n ${ }^{\circ}$ 885/2008)], Cadiar [STJS de Andalucía/Granada de 13 de julio de 2015 (recurso n ${ }^{\circ}$ 285/2013)], Sayalonga [STSJ de Andalucía/Málaga de 5 de febrero de 2016 (recurso n ${ }^{\circ}$ 1445/2014)], Carataunas [STJS de Andalucía/ Granada de 20 de abril de 2015 (recurso n ${ }^{\circ}$ 1207/2010)], La Guardia [STJS de Andalucía/Granada de 18 de mayo de 2015 (recurso n ${ }^{\circ}$ 985/2012)], Íllora [STJS de Andalucía/Granada de 30 de marzo de 2015 (recurso n $^{\circ}$ 957/2010)], Adra [STJS de Andalucía/Granada de 14 de diciembre de 2015 (recurso n ${ }^{\circ}$ 424/2014)], Cantoria [SSTJS de Andalucía/Granada de 11 y 18 de mayo de 2015 (recursos n ${ }^{\circ}$ 828/2012 y 1118/2012)] o Fines [STJS de Andalucía/Granada de 14 de marzo de 2016 (recurso n ${ }^{\circ}$ 229/2015)]. 
tivo por parte de la Generalidad habría comenzado a correr transcurrido un mes desde el requerimiento, en lugar de los tres meses que esperó. Recurrida en apelación la sentencia, el Tribunal Superior de Justicia de Cataluña estimó el recurso y, por cuanto aquí importa ahora, afirmó que la Administración de la Comunidad Autónoma de Cataluña estaba legitimada para solicitar la revisión de oficio de la licencia.

El razonamiento que llevó a la sentencia a alcanzar la anterior conclusión se basaba, exclusivamente, en una interpretación bastante discutible de la normativa urbanística catalana vigente en ese momento y que, a su vez, se remitía a la regulación sobre revisión de oficio de la LPA de 1958. De acuerdo con el art. 258.1 del Decreto Legislativo 1/1990, por el que se aprobaba el texto refundido de los textos legales vigentes en Cataluña en materia urbanística,

«Las licencias u órdenes de ejecución cuyo contenido constituya alguna de las infracciones urbanísticas graves definidas en esta ley deberán de ser revisadas dentro de los cuatro años desde la fecha de su expedición por la Corporación municipal que las otorgó a través de alguno de los procedimientos del artículo 110 de la Ley de Procedimiento Administrativo, bien de oficio o a instancia del Consejero de Política Territorial y Obras Públicas $(\ldots) »$.

El art. 110 LPA (a diferencia de lo que finalmente se establecería en el art. 103 LRJPAC tras la reforma de la Ley 4/1999) admitía la revisión de oficio de actos anulables, a los que va referido el artículo transcrito. Lo que no preveía, de ningún modo, era que dicha revisión de oficio de actos anulables pudiera producirse a solicitud de interesado, por lo que el art. 258.1 del Decreto Legislativo 1/1990 en ningún caso podía prever que el Consejero de Política Territorial y Obras Públicas tuviera una acción para iniciar el procedimiento de revisión. Mucho más modestamente, y como literalmente recogía el artículo transcrito, la Administración autonómica solo podía «instar», es decir, incitar a la Corporación local autora del acto a proceder a su revisión. Nada más.

Sin embargo, la sentencia se dicta cuando ya se encontraba derogada la LPA y, por tanto, cuando el antiguo art. 110 LPA había sido sustituido por el art. 103 LRJPAC. La redacción originaria de este precepto, posteriormente modificada por la Ley 4/1999, permitía a la Administración autora de un acto anulable proceder a su revisión de oficio cuando este infringiera «gravemente normas de rango legal o reglamentario» y, como novedad, preveía también que la revisión de oficio se produjera «a iniciativa propia o a solicitud del interesado».

Para ser respetuosa con ese art. 103 LRJPAC, la sentencia debería haber afirmado el carácter de interesada de la Administración autonómica y, por tanto, la posibilidad de que solicitara la revisión de oficio «a solicitud de interesado» prevista en el 
precepto. Sin embargo, la sentencia no llega a afirmar que la Administración tenga el carácter de «interesada» e incluso, más bien, lo niega. En lugar de ello, y de manera un tanto críptica, descubre una tercera vía entre revisión de oficio y revisión a solicitud de interesado. Según la sentencia, la posibilidad de «instar», reconocida en el art. 258.1 del Decreto Legislativo 1/1990, obligaría, también, a la revisión de oficio del acto impugnado y, en caso de no hacerse por la entidad local, permitiría el acceso a la jurisdicción contencioso-administrativa:

«cuando de lo que se trata es de privar de efectos y hacer desaparecer del mundo jurídico el título habilitante consistente en una licencia de la naturaleza que se ha expuesto por la vía de la revisión de oficio, más allá de los estrictos términos del artículo 103 de la Ley 30/1992 -que habilita a la propia Administración autora del acto y a los interesados-, habrá que convenir que la actuación de la Administración Autonómica no solo no queda diluida en la mera conceptuación de interesado en términos generales sino que resulta expresa y expresivamente destacada y resaltada (...) en el invocado artículo 258 del Decreto Legislativo 1/1990, para la debida consecución de los fines, objetivos y funciones urbanísticos de rigor, sin merma sino en claro reconocimiento del principio de autonomía local, al ser ante el ente local correspondiente donde la Administración Autonómica debe instar la revisión de oficio correspondiente para, en su caso, finalmente acceder a la Jurisdicción Contencioso Administrativa».

«De todo ello y sin perjuicio de otras posibilidades o vías, cabe inferir el perfecto ajuste a Derecho de la solicitud efectuada de revisión de oficio ante la Administración Municipal (...) -con cobertura sobrada en el reiteradamente invocado artículo 258 del Decreto Legislativo 1/1990- y ya en la vía del artículo 103 de la Ley 30/1992».

Sin perjuicio de lo que más adelante se dirá sobre el alcance que puede tener esta potestad de «instar» la revisión de oficio de otra Administración, entendida como una forma de mera denuncia, importa ahora destacar dos elementos del razonamiento de la STSJ de Cataluña de 25 de octubre de 2001 (recurso n ${ }^{\circ}$ 137/2001) objeto de análisis:

- en primer lugar, toda la construcción se basa en la remisión del art. 258.1 del Decreto Legislativo 1/1990 al art. 110 LPA; artículo que ya había sido sustituido por el art. 103 LRJPAC;

- en segundo lugar, en ningún momento se afirma que la Administración autonómica tenga el carácter de interesada para solicitar una revisión de oficio.

Esta discutible jurisprudencia debía haber terminado con la reforma operada en la LRJPAC por parte de la Ley 4/1999. En efecto, como se ha recordado más 
atrás, el art. 103 LRJPAC (actual art. 107 LPAG) admitía en su redacción originaria la revisión de oficio del acto anulable que infringiera «gravemente normas de rango legal o reglamentario». Sin embargo, a partir de la modificación introducida por la Ley 4/1999, desapareció la revisión de oficio de los actos anulables, siendo sustituida para todos los casos por el régimen de impugnación ante los órganos de lo contencioso-administrativo, previa declaración de lesividad. La revisión de oficio quedó así reservada al supuesto de actos nulos de pleno derecho recogido en el art. 102 LRJPAC (actual art. 106 LPAC), al que en ningún caso hacía referencia el art. 258.1 del Decreto Legislativo 1/1990 (que, insistimos, se refería al art. 110 LPA) ${ }^{18}$. Por consiguiente, esta modificación impedía seguir usando el art. 258.1 del Decreto Legislativo 1/1990 como base para afirmar la legitimación de la Administración autonómica para exigir la revisión de oficio de los actos de las Entidades locales.

Sin embargo, de manera sorprendente y sin justificación alguna, la STSJ de

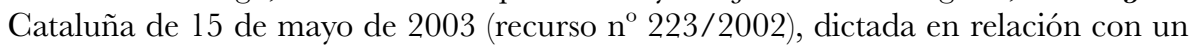
supuesto sustancialmente idéntico ${ }^{19}$, dice asumir «íntegramente» la doctrina de la ya analizada STSJS de 25 de octubre de 2001 (recurso n ${ }^{\circ} 137 / 2001$ ) y concluye que

«la solicitud de revisión de oficio efectuada ante el Ayuntamiento el 7-8-2000 tiene plena cobertura en el art. 258 [Decreto Legislativo 1/1990] (...), ya en la vía del art. 102 de la Ley 30/1992 de 26-1 1, de Régimen Jurídico de las Administraciones Públicas y del Procedimiento Administrativo Común, en la redacción dada por la Ley 4/1999».

La sentencia no entra a analizar en ningún momento el art. 102 LRJPAC, ni si la Administración autonómica puede considerarse «interesada» a efectos de solicitar la revisión de oficio. Simplemente se remite a la sentencia anterior y sustituye las referencias al art. 103 LRJPAC por las nuevas referencias al art. 102 LRJPAC.

Todo parece un gran malentendido sobre la base de una interpretación errónea previa. Y, lo que es peor, esta jurisprudencia se repite acríticamente en toda una serie de sentencias posteriores que empiezan a considerar, sin más base que el citado pronunciamiento, que la Administración está amparada por el art. 102 LRJPAC:

18 En efecto, el antecedente inmediato del art. 102 LRJPAC (actual art. 106 LPAC), era el art. 109 LPA, que establecía que «La Administración podrá en cualquier momento, de oficio o a instancia del interesado, y previo dictamen favorable del Consejo de Estado, declarar la nulidad de los actos enumerados en el artículo cuarenta y siete», en el que se enumeraban los actos nulos de pleno derecho.

19 En el caso de la STSJ de Cataluña de 15 de mayo de 2003 (recurso n ${ }^{\circ}$ 223/2002), el Ayuntamiento de Malgrat de Mar concedió una licencia de obra con fecha de 23/09/1999. Posteriormente, la Generalidad de Cataluña presentó una solicitud, con fecha de 07/08/2000, para que se procediera a la revisión de oficio de dicha licencia de conformidad con lo previsto en el art. 102.1 LRJPAC. 
- STSJ de Cataluña de 29 de octubre de 2003 (recurso no 61/2003), Ayuntamiento de Gerona ${ }^{20}$;

- STJS de Cataluña de 10 de junio de 2004 (recurso no 241/2003), Ayuntamiento de Sant Just Desvern;

- STSJ de Cataluña de 16 de septiembre de 2004 (recurso n 262/2003), Ayuntamiento de La Garriga;

- STSJ de Cataluña de 22 de septiembre de 2005 (recurso n ${ }^{\circ}$ 167/2005), Ayuntamiento de Vilanova d'Escornalbou;

- STSJ de Cataluña de 8 de noviembre de 2006 (recurso n ${ }^{\circ}$ 582/2003), Ayuntamiento de Planoles (en relación con la aprobación de una modificación de estudio de detalle);

- STJS de Cataluña de 7 de febrero de 2008 (recurso no 400/2004), Ayuntamiento de l'Ampolla (en relación con la aprobación de una modificación de estudio de detalle)

Pero la relevancia de esta jurisprudencia no se agota aquí. A pesar de sus defectos congénitos, su éxito es tal que será reproducida por otros Tribunales Superiores de Justicia, con o sin mención expresa a ella. De este modo, simplemente se sustituyen las referencias a la normativa urbanística catalana por referencias a la normativa urbanística autonómica correspondiente.

Así ocurre con la STSJ de Galicia de 19 de octubre de 2006 (recurso ${ }^{\circ}$ 4275/2004). En los hechos, la Junta de Galicia requirió al Ayuntamiento de A Guarda para que procediera a la revisión de oficio de varias licencias, tomando como base el art. 102 LRJPAC. El Ayuntamiento negaba la legitimación de la Administración autonómica por considerar que no existía otra vía para que esta Administración pudiera obtener la anulación de una licencia municipal que la señalada en los artículos 65 y 66 de la LRBRL. Sin embargo, la sentencia considera que la Junta de Galicia acudió co-

20 A fuer de ser precisos, esta sentencia no coincide exactamente con la STSJ de Cataluña de 15 de mayo de 2003 (recurso n ${ }^{\circ} 223 / 2002$ ), a la que no cita, pero sus argumentos sí son plenamente coincidentes. Afirma esta sentencia en su FJ $1^{\circ}$, refiriéndose a la revisión de oficio del art. 102.1 LRPAC, que «si en algunos casos tal declaración se ha realizado respecto de simples particulares, no existe razón alguna por la cual deba la Administración Autonómica considerarse a los efectos con menor derecho, más cuando, hallándonos en materia urbanística, y en el ámbito geográfico de Cataluña (...) su propio artículo 258.1 impone en todo caso que las licencias u órdenes de ejecución cuyo contenido constituya alguna de las infracciones urbanísticas graves en él definidas sean revisadas dentro de los cuatro años desde la fecha de su expedición por la Corporación Municipal que las otorgó a través de alguno de los procedimientos prevenidos en el artículo 103 de la Ley 30/1.992, bien de oficio o a instancia del Consejero de Política Territorial y Obras Públicas». Esta sentencia es objeto expreso del comentario de Rebollo Puig, Manuel (2010): 455-457. 
rrectamente a la «solicitud de revisión de la licencia, solicitud que cualquier interesado puede formular a la Administración de acuerdo con lo previsto en el artículo 102 de la Ley 30/92, y la Xunta de Galicia al Alcalde, según lo previsto en los artículos 180.2 y 179 de la Ley del Suelo de Galicia». Los artículos de la Ley del Suelo de Galicia citados son prácticamente idénticos a los recogidos en el Decreto Legislativol/1990 catalán, cuya errónea interpretación sirvió de base, como vimos, a la admisión de la legitimación de la Administración catalana para solicitar la revisión de oficio ${ }^{21}$. Es decir, en ningún momento atribuyen la condición de interesada a la Administración autonómica gallega sino que, mucho más modestamente, prevén que el órgano autonómico competente pueda instar a la Entidad local autora del acto a que proceda a su revisión de oficio.

Sin embargo, también esta sentencia es tomada como modelo y repetida en sus mismos términos por otros pronunciamientos posteriores, que la asumen sin cuestionarla:

- SSTSJ de Galicia de 29 de abril, 6 de mayo, 23 de septiembre y 25 de noviembre de 2010 (recursos $n^{\circ} 4816 / 2008,4330 / 2008,4602 / 2009$ y 4600/2009, respectivamente), todas ellas referidas al Ayuntamiento de Fisterra;

- STJS de Galicia de 24 de junio de 2010 (recurso n 4505/2008), Ayuntamiento de A Guarda.

Por su parte, el Tribunal de Justicia de Andalucía/Málaga tomará abiertamente como base la jurisprudencia elaborada por el Tribunal de Justicia de Cataluña, citándola de manera expresa, para afirmar que la Administración andaluza se encuentra también legitimada para solicitar la revisión de oficio de los actos adoptados por las Entidades locales andaluzas. La recepción de dicha jurisprudencia se produce en la STSJ de Andalucía/Málaga de 1 de octubre de 2008 (recurso n ${ }^{\circ} 2227$ /2007), recaída sobre un asunto muy similar a todos los que resuelven las sentencias ya comentadas. En este caso, la Junta de Andalucía había solicitado al Ayuntamiento de Gaucín que procediera a la revisión de oficio del acuerdo que aprobaba un proyecto de actuación para la construcción de una vivienda unifamiliar en suelo urbanizable. Nuevamente, el Ayuntamiento requerido inadmitió la solicitud al entender que no cabe un planteamiento revisor de una actuación urbanística por la Administración autonómica fuera

${ }^{21} \quad$ El art. 179 de la ya derogada Ley 1/1997, de 24 de marzo, del Suelo de Galicia establecía que «Cuando el contenido de las licencias u órdenes de ejecución constituya manifiestamente alguna de las infracciones urbanísticas graves o muy graves previstas en esta Ley, deberán ser revisadas dentro de los cuatro años desde la fecha de su expedición por el Ayuntamiento que la otorgó a través de alguno de los procedimientos de revisión de oficio contemplados en la Ley 30/1992, de 26 de noviembre».

Por su parte, el art. 180.2 de la misma Ley, disponía que «Las licencias u órdenes de ejecución que se otorgasen con infracción de la zonificación o uso urbanístico de las zonas verdes, espacios libres, dotaciones, equipamientos o suelo rústico con especial protección previstos en el planeamiento serán nulas de pleno derecho. En estos casos, el Consejero de Política Territorial, Obras Públicas y Vivienda requerirá al Alcalde para que proceda según lo dispuesto en los artículos 178 y 179 anteriores». 
de los cauces de los arts. 65 a 67 LRBRL. La sentencia, sin embargo, rechazó esta interpretación y, como único fundamento, transcribió literalmente buena parte de la STSJ de Cataluña de 22 de septiembre de 2005 (recurso n ${ }^{\circ}$ 167/2005), recaída en relación con el Ayuntamiento de Vilanova d'Escornalbou, antes citada, limitándose a añadir que «en la legislación autonómica andaluza existe un precepto similar al señalado por la legislación catalana, en concreto, el artículo 190 de la LOUA [Ley 7/2002, de 17 de diciembre, de Ordenación Urbanística de Andalucía]».

El citado art. 190 LOUA viene a coincidir, ciertamente, con los preceptos equivalentes de las normativas catalana y gallega. Sin embargo, en su caso ni tan siquiera se incluye la previsión de que el órgano autonómico andaluz competente pueda «instar» la revisión de oficio a las Entidades locales autoras del acto. Previsión, por otra parte, innecesaria por superflua ${ }^{22}$.

Con tan escueta argumentación, la sentencia consideró justificada la legitimación de la Administración autonómica para solicitar la revisión de oficio del acuerdo del Ayuntamiento y, como consecuencia, estimó el recurso interpuesto por la Junta de Andalucía, ordenando al Ayuntamiento de Gaucín que continuara con la tramitación del procedimiento de revisión de oficio solicitado por aquella ${ }^{23}$.

A partir de esta sentencia, el Tribunal Superior de Justicia de Andalucía/Málaga mantendrá la misma postura una y otra vez, con reproducción de sus mismos fundamentos:

- STSJ de Andalucía/Málaga de 25 de febrero de 2009 (recurso no 2684/2008), Ayuntamiento de Cómpeta;

- STSJ de Andalucía/Málaga de 6 de marzo de 2009 (recurso nº 2147/2008), Ayuntamiento de Ronda;

- STJS de Andalucía/Málaga de 4 de septiembre de 2009 (recurso no 939/2009), Ayuntamiento de Marbella ${ }^{24}$.

${ }^{22}$ En concreto, el art. 190.1 LOUA establece que «Sin perjuicio de lo dispuesto en el artículo anterior, las licencias urbanísticas y las órdenes de ejecución, así como cualquier otro acto administrativo previsto en esta Ley, cuyo contenido constituya o habilite de manera manifiesta alguna de las infracciones urbanísticas graves o muy graves definidas en esta Ley, deberán ser objeto de revisión por el órgano competente, de conformidad con lo establecido en legislación reguladora del régimen jurídico de las Administraciones públicas y del procedimiento administrativo común».

${ }_{23}$ Esta sentencia, sin embargo, será recurrida ante el Tribunal Supremo y dará lugar al primer pronunciamiento del Alto Tribunal sobre esta cuestión, la STS de 29 de septiembre de $2010\left(\right.$ recurso $\mathrm{n}^{\circ}$ 12/2009, ponente: FERnández VALVERDE), sobre la que volveremos en el siguiente epígrafe.

${ }_{24}$ Este último pronunciamiento cita, sin embargo, una sentencia distinta aunque enmarcada en la misma línea jurisprudencial: la STSJ de Cataluña de 29 de octubre de 2003 (recurso nº 61/2003), Ayuntamiento de Gerona, también analizada más atrás. 
En conclusión, entre 2001 y 2009 se sucede una nutrida serie de pronunciamientos de tres Tribunales Superiores de Justicia, vinculados entre sí y basados en unos mismos argumentos, que, sin embargo, en ningún momento justifican que la Administración autonómica tenga el carácter de interesada para solicitar una revisión de oficio al amparo del art. 102.1 LRJPAC (hoy art. 106 LPAC). Cada una de estas sentencias se limita a citar a las sentencias anteriores, ignorando que la sentencia que inauguró la línea no se refería al art.102.1 LJRPAC, sino al art. 103 LRJPAC, y que no afirmó en ningún momento que la Administración autonómica pudiera considerarse sujeto interesado para solicitar una revisión de oficio.

Salvo error, el único intento de afirmar el carácter de sujeto interesado a los efectos de solicitar la revisión de oficio del art. 102.1 LRJPAC se encuentra en la STSJ de Cataluña de 3 de abril de 2009 (recurso n ${ }^{\circ}$ 268/2008), relativa a la solicitud de revisión de oficio dirigida por la Generalidad de Cataluña contra una licencia de uso y primera ocupación concedida por el Ayuntamiento de Tarragona. Esta sentencia omite toda mención a la anterior línea jurisprudencial y resuelve el problema de la legitimación de la Administración autonómica para solicitar la revisión de oficio afirmando que esta le viene concedida gracias a la acción popular propia de la materia urbanística:

«como bien dice la Generalitat de Catalunya, esta ostenta legitimación activa para ejercitar la revisión de oficio de la licencia de uso y primera ocupación en base a la acción pública que establece el artículo 12, en relación con el artículo 200.2, ambos de la Ley 2/2002, de Urbanismo».

$\mathrm{El}$ argumento empleado no constituye una absoluta novedad ${ }^{25}$, pero lo que importa destacar es que esta sentencia, que afortunadamente no encuentra continuidad en otras posteriores, ignora la jurisprudencia constante del Tribunal Supremo que ha rechazado que las Administraciones de control puedan ejercer la acción popular contra las actuaciones de las Administraciones locales en materia urbanística cuando han transcurrido los plazos para que pudieran impugnarlos por la vía del art. $65 \mathrm{LRBRL}^{26}$.

25 En realidad, las menciones a la acción popular en materia urbanística se suceden desde la originaria STSJ de Cataluña de 25 de octubre de 2001 (recurso ${ }^{\circ}$ 137/2001), si bien de manera indirecta y sin hacer descansar sobre ella el razonamiento de estas sentencias, que suele iniciarse diciendo «sin necesidad de abundar sobre el ejercicio de la acción pública urbanística...».

26 La STS de 25 de septiembre de 2002 (recurso nº 9819/1997, ponente: ENRÍQuez SANCHO), aclaraba que «no cabe hablar de una interpretación integradora del artículo 65 L.B.R.L., en atención a los artículos 235 y 187 T.R.L.S. de modo que los plazos de impugnación que establece aquel precepto queden sin efecto en materia urbanística, hasta tal punto de prevalecer el de cuatro años previsto en este último. No cabe aceptar este criterio, porque no se trata de integrar algún elemento de la norma sino el de sustituir el plazo claramente establecido en ella por otro». En este sentido, y con cita expresa de esta misma sentencia, Rebollo Puig, Manuel (2010): 477 y las autoras ya citadas en la nota 15 de este trabajo. 


\section{EL PRIMER ACERGAMIENTO DEL TRIBUNAL SUPREMO A LA MATERIA, EN EL QUE AMAGA, PERO NO DA, Y COMPLI- GA INNEGESARIAMENTE EL DEBATE}

El primer pronunciamiento del Tribunal Supremo sobre esta materia tiene lugar en 2010 y toma como base, precisamente, una de las sentencias antes referidas. En concreto, la STS de 29 de septiembre de 2010 (recurso n ${ }^{\circ}$ 12/2009, ponente: FERnÁnDEZ VALVERDE), se dicta como consecuencia del recurso de casación en interés de la Ley interpuesto por el Ayuntamiento de Gaucín contra la STSJ de Andalucía/Málaga de 1 de octubre de 2008 (recurso n $\left.{ }^{\circ} 2227 / 2007\right)^{27}$.

Como se recordará, esta sentencia, que introdujo en la jurisprudencia del TSJ de Andalucía/Málaga la línea desarrollada por el TSJ de Cataluña, estimó el recurso presentado por la Junta de Andalucía contra la inadmisión, por parte del Ayuntamiento de Gaucín, de una solicitud de revisión de oficio dirigida contra el acuerdo de este último por el que se aprobaba un proyecto de actuación para la construcción de una vivienda unifamiliar en suelo urbanizable.

Contra esta sentencia, el Ayuntamiento de Gaucín interpuso recurso de casación en interés de la Ley proponiendo la fijación de la siguiente doctrina legal:

«En los supuestos establecidos en los artículos 65 y 66 de la Ley 7/1985, de 2 de abril, las Comunidades Autónomas no pueden impugnar los actos y acuerdos en que se den las circunstancias en ellos previstas mediante la solicitud de revisión de oficio de aquellos y la posterior impugnación contencioso-administrativo contra la inadmisión o desestimación de tal solicitud, debiendo someterse la impugnación de aquellos actos y acuerdos, en todo caso, a las formas y plazos establecidos en los preceptos de la citada Ley».

Sin embargo, el Tribunal Supremo rechaza fijar la doctrina legal propuesta y declara no haber lugar al recurso de casación. Ello se debe, en buena medida, al modo parcialmente erróneo en que la sentencia fija los términos del debate. En un primer momento, la sentencia acierta al centrarse en analizar el ámbito subjetivo de la expresión «a solicitud de interesado» del art. 102.1 LRJPAC y, «más en concreto, si (...) puede incluirse, en el ámbito subjetivo del mismo, no solamente a los particulares, sino también (...) a la Comunidad Autónoma, en el supuesto de que la Administración de la que se pretende el inicio del procedimiento de revisión de oficio, se trate de una Administración local». La conclusión a la que llega la sentencia es favorable

27 En relación con esta sentencia, véase el comentario de Rebollo Puig, Manuel (2012): in toto, donde se actualizan y reelaboran muchos de los argumentos ya desarrollados en Rebollo Puig, Manuel (2010). 
a que dentro del concepto «interesado» utilizado por el art. 102.1 LRJPAC puedan entenderse incluidos tanto particulares como otras Administraciones públicas distintas de la autora del acto $^{28}$.

Pero, aceptado lo anterior (que, en realidad, nadie negaba realmente), la sentencia se detiene en su razonamiento y no entra a resolver el verdadero conflicto: ¿debe acreditar la Administración autonómica que solicita la revisión de oficio de un acto dictado por una Administración local el estar en posesión de un derecho subjetivo o interés legítimo que justifique su condición de «interesada» exigido por el art. 102.1 LRJPAC? ¿O le basta, por el contrario, su simple condición de «Administración superior» y defensora genérica de la legalidad para entender que goza de una legitimación general (como en el art. 65 LRBRL) y poder solicitar dicha revisión?

La cuestión quedaba irresuelta y es importante insistir en ello: la STS de 29 de septiembre de 2010 (recurso n ${ }^{\circ}$ 12/2009, ponente: FERNÁNDEZ VALVERDE) en ningún momento afirmó que la Administración autonómica gozara de una legitimación general que le permitiera acudir libremente a la vía del art. 102.1 LRJPAC para solicitar la revisión de oficio de actos nulos adoptados por una Administración local o que no debiera acreditar su condición de «interesada» entendida en el sentido del art. 31 LRJPAC (actual art. 4 LPAC).

Por lo demás, la principal crítica a esta sentencia no debe dirigirse a que dejó escapar la oportunidad de entrar y resolver el fondo del debate, sino al hecho de que pareció admitir la revisión de oficio, a solicitud de interesado, no solo de actos sino también de reglamentos. Y ello a pesar de que la revisión de oficio de estos últimos no se regulaba en el art. 102.1 LRJPAC (actual art. 106.1 LPAG), sino en el art. 102.2 LRJPAC (actual art. 106.2 LPAC), en el que de ningún modo se admitía la revisión a solicitud de interesado.

En particular, la aparente admisión de esta revisión de oficio de reglamentos «a solicitud de interesado» se deducía de dos elementos distintos. Por un lado, debe recordarse que el objeto del asunto era la solicitud, por parte de la Junta de Anda-

${ }^{28}$ Los razonamientos seguidos por la sentencia para llegar a esta conclusión no son un dechado de claridad, dado que a lo largo del Fundamento Jurídico $4^{\circ}$ parece sostenerse, sucesivamente, que el concepto de «interesado» del art. 31 LRJPAC (actual art. 4 LPAC) se aplica y no se aplica a las Administraciones públicas y que la impugnación de actos locales por parte de las Administraciones superiores puede y no puede hacerse solo por las vías ofrecidas por la LRBRL. En última instancia, el argumento que sirve a la sentencia para justificar que las Administraciones públicas puedan solicitarse mutuamente la revisión de oficio de sus actos (es decir, que puedan entenderse incluidas en el concepto de «interesado» del art. 102.1 LRJPAC) es que «el legislador ha excluido en este tipo de conflictos [interadministrativos] los recursos administrativos, pero no la solicitud de revisión de oficio, como podía haber hecho, de una forma expresa», por lo que, en sentido contrario, esta posibilidad debe entenderse admitida. En el Fundamento Jurídico $5^{\circ}$, asimismo, se rechaza que esta posibilidad pueda suponer una vulneración de la autonomía local. 
lucía, de que el Ayuntamiento de Gaucín revisara la aprobación de un proyecto de actuación para la construcción de una vivienda unifamiliar en suelo urbanizable; proyecto de actuación que en realidad tenía naturaleza normativa ${ }^{29}$. En consecuencia, al afirmar la «adecuada utilización por parte de la Junta de Andalucía del procedimiento de revisión de oficio prevenido en el citado artículo 102 de la LRJPAC», la sentencia estaba admitiendo, tal vez sin ser plenamente consciente, la revisión de oficio a solicitud de interesado de una norma reglamentaria. Por otro lado, una desafortunada redacción de otro pasaje de la misma sentencia parecía admitir, ahora expresamente, que la Administración autonómica podía instar la revisión de oficio de los reglamentos de las Administraciones locales ${ }^{30}$.

De manera completamente innecesaria se abría, por tanto, un nuevo debate sobre un punto que parecía absolutamente claro tanto en la ley como en la jurisprudencia ${ }^{31}$ y que aún generaría ciertas ambigüedades en la jurisprudencia posterior del Tribunal Supremo ${ }^{32}$. La situación de ambigüedad, de hecho, no concluyó hasta que, casi cinco años después, el Alto Tribunal se desdijo expresamente

29 Así lo han señalado en la doctrina, entre otros, Mariano LóPEz Benítez, «Ordenación urbanística y derecho de propiedad», en Manuel Rebollo Puig (coord.), Derecho urbanístico y ordenación del territorio en Andalucia, Iustel, Madrid, 2007, pp. 326-327, o el propio Rebollo Puig, Manuel (2012): 2021.

$30 \mathrm{Al}$ final del Fundamento Jurídico $4^{\circ}$ la sentencia afirma que «la Administración autonómica está legitimada en los dos apartados del 102 (actos administrativos y disposiciones generales) y puede instar, como interesada, de las Administraciones que integran la Administración Local, el inicio del procedimiento de revisión de oficio de los actos administrativos y -con exclusividad- de las disposiciones generales».

31 El tenor de la ley es claro y la doctrina ha sido unánime en su interpretación: solo la Administración autora del reglamento puede iniciar el procedimiento de revisión de oficio. Así se deduce de una simple interpretación sistemática de los arts. 106.1 y 106.2 LPAC: mientras el primero comienza indicando «Las Administraciones Públicas, en cualquier momento, por iniciativa propia o a solicitud de interesado (...)» el segundo se limita a decir «Asimismo, en cualquier momento, las Administraciones Públicas de oficio (...)». Se trata, además, de una opción legislativa coherente con la prohibición de que los administrados puedan interponer recursos en vía administrativa contra las disposiciones administrativas de carácter general (art. 112.3 LPCAP). Sobre todo ello, Bueno Armijo, Antonio (2016): 397.

Del mismo modo, la jurisprudencia del TS también había rechazado tajantemente hasta ese momento la posibilidad de que el procedimiento de revisión de oficio de normas administrativas pudiera iniciarse a solicitud de interesado. Cfr., entre otras muchas: SSTS de 16 de noviembre de 2006 (recurso $n^{\circ}$ 4014/2003, ponente: Peces Morate) y de 25 de mayo de 2010 (recurso n ${ }^{\circ}$ 2687/2010, ponente: Peces Morate).

32 Algunos pronunciamientos posteriores a esta desconcertante STS de 29 de septiembre de 2010 (recurso no 12/2009, ponente: FERNÁNDEZ VALVERDE) recogieron literalmente el equívoco párrafo transcrito en la nota 30 de este trabajo, sin aclarar su contenido, como la STS de 24 de marzo de 2011 (recurso ${ }^{\circ}$ 1548/2007, ponente: Fernández VALVERde). Otros pronunciamientos, refiriéndose también expresamente a la innovación contenida en la citada sentencia, se mostraron algo ambiguos y ni afirmaron ni rechazaron lo sostenido en ella (aunque el hecho de no afirmarlo podía ser también indicativo de que debió tratarse de un error), negándose de manera expresa a pronunciarse sobre ello. Es el caso de las SSTS de 11 de octubre de 2012 (recurso n ${ }^{\circ}$ 3871/2010, ponente: Calvo Rojas), de 11 de abril de 2013 (recurso n ${ }^{\circ}$ 598/2011, ponente: Calvo Rojas) y de 17 de abril de 2013 (recurso n ${ }^{\circ}: 5548 / 2011$, ponente: Fernández Valverde). 
de lo contenido en esta sentencia y confirmó, nuevamente, que el art. 106.2 LPAC no permite iniciar el procedimiento de revisión de oficio de normas administrativas a solicitud de interesado ${ }^{33}$.

En cualquier caso, y por cuanto afecta al objeto de este trabajo, la principal consecuencia de la STS de 29 de septiembre de 2010 (recurso n ${ }^{\circ}$ 12/2009, ponente: FERNÁNDEZ VALVERDE) fue que sería empleada para reforzar su posición por los Tribunales Superiores de Justicia que venían reconociendo la legitimación de la Administración autonómica para solicitar la revisión de oficio de los actos de las Entidades locales.

Así ocurrirá, destacadamente, con el TSJ de Andalucía/Málaga, que reproducirá extensamente esta sentencia en los siguientes pronunciamientos que se verá obligado a emitir en relación con supuestos similares, completando, y no sustituyendo, su anterior línea argumental ${ }^{34}$. Como novedad, también el TSJ de Andalucía/Sevilla se sumará a esta misma línea ${ }^{35}$. Los demás Tribunales Superiores de Justicia, por su parte, se limitan sencillamente a mantener y repetir sus jurisprudencias previas, sin considerar necesario acudir a este pronunciamiento del Tribunal Supremo (TSJ de

33 La aclaración definitiva se produjo en la STS de 21 de mayo de 2015 (recurso n ${ }^{\circ}$ 3004/2012, ponente: DE Oro-Pulido López). En los hechos, la Junta de Andalucía había solicitado la revisión de oficio de un acuerdo del Pleno del Ayuntamiento de Ayamonte por el que se aprobaba definitivamente un estudio de detalle. El Ayuntamiento inadmitió la solicitud al entender que el art. 102.2 LRJPAC no permitía la revisión de oficio de normas administrativas a solicitud de interesado y la Junta de Andalucía recurrió la inadmisión alegando, precisamente, que esta posibilidad había sido aceptada por la tan citada STS de 29 de septiembre de 2010. Obligado a pronunciarse abiertamente sobre lo que se resolvió en esa sentencia, el Tribunal Supremo se limita ahora a indicar que «las consideraciones que en aquella se contienen en orden a la legitimación de la Administración Autónoma para pedir la revisión de oficio de normas reglamentarias locales no constituye la ratio decidendi del fallo de la sentencia, sino un simple obiter dicta» y reproduce su jurisprudencia previa y constante en la que siempre se había rechazado esta posibilidad $\left(\mathrm{FJ} 3^{\circ}\right)$. La sentencia pasa de puntillas, eso sí, sobre el dato insoslayable de que la STS de 29 de septiembre de 2010, de hecho, admitió la revisión de oficio de una norma reglamentaria local a solicitud de una Administración autonómica.

34 Cfr., muy especialmente, la STSJ de Andalucía/Málaga de 14 de octubre de 2014 (recurso n ${ }^{\circ}$ 692/2011), en relación con un proyecto de actuación aprobado por el Pleno del Ayuntamiento de Cómpeta; la STSJ de Andalucía/Málaga de 30 de diciembre de 2014 (recurso no 1114/2012), relativo a un proyecto de actuación aprobado por el Pleno del Ayuntamiento de Sayalonga; o la STSJ de Andalucía/Málaga de 5 de febrero de 2016 (recurso $n^{\circ} 1445 / 2004$ ), relativa a otro proyecto de actuación aprobado también por el Pleno de este último Ayuntamiento.

35 STSJ de Andalucía/Sevilla de 26 de noviembre de 2010 (recurso nº 679/2008), que, con muy discutible técnica, se limita a copiar íntegramente la sentencia del Tribunal Supremo, marcando en negrita «aquello que resulta fundamental para la resolución del presente» y a añadir, después de la transcripción: «Y, de conformidad con lo que el TS señala, el presente recurso de apelación ha de ser estimado», con lo que cierra la sentencia, sin hacer ni una sola referencia a los hechos del caso enjuiciado. 
Galicia $^{36}$ ) o, en ocasiones, sin ni siquiera aportar un razonamiento específico (TSJ de Cataluña ${ }^{37}$ ).

\section{LA INESPERADA APARICIÓN DEL TRIBUNAL SUPERIOR DE JUSTICIA DE ANDALUCÍA/GRANADA Y SU NEGATIVA A ACEPTAR LA LEGITIMACIÓN GENERAL DE LA ADMINIS- TRAGIÓN AUTONÓMICA PARA SOLIGITAR LA REVISIÓN DE OFICIO}

Recapitulemos. A la altura de septiembre de 2010, varias Administraciones autonómicas estaban haciendo uso de la vía del art. 102.1 LRJPAC para solicitar la revisión de oficio de actos (e incluso reglamentos) adoptados por las Administraciones locales, aun sin contar con el carácter de «interesadas» exigido por el precepto. Con estas solicitudes de revisión, las Administraciones autonómicas evitaban que la superación de los plazos impuestos por los arts. 65 LRBRL y 44 y 46.6 LJCA les impidiese actuar contra tales actos. Los Tribunales Superiores de Justicia que habían conocido del asunto se habían pronunciado favorablemente a los intereses de las Administraciones autonómicas, si bien para ello habían tenido que desarrollar una jurisprudencia basada en premisas erróneas, pero repetida y compartida hasta quedar ampliamente consolidada. Finalmente, en la primera ocasión en que pudo conocer de esta controversia, el Tribunal Supremo, en un desafortunado pronunciamiento, reconoció que las Administraciones autonómicas podían solicitar la revisión de oficio prevista en el art. 102.1 LJRPAC, «como cualquier interesado», pero no llegó a aclarar si, a tal efecto, debían acreditar la concurrencia de un derecho subjetivo o un interés legítimo (justamente, como cualquier interesado). Al no rechazar la solución que venían ofreciendo los Tribunales Superiores de Justicia, estos se sintieron reforzados y se mantuvieron firmes en sus postulados previos. Como consecuencia, y como advirtió la mejor doctrina de que podría ocurrir, algunas Administraciones autonómicas parece que se sintieron tentadas a «explotar» aún más esta vía cada vez que se les pasaran los plazos de los artículos 65 y 66 LRBRL $^{38}$. Tentación, por cierto, que la Administración de la Comunidad Autónoma de Andalucía no fue capaz de resistir, según dejamos indicado en un epígrafe anterior.

36 En esta línea pueden encontrarse la STJS de Galicia de 13 de enero de 2011 (recurso $\mathrm{n}^{\circ}$ 4195/2010), Ayuntamiento de Porto do Son y Adoración; las SSTSJ de Galicia de 19 de mayo de 2011 y 12 de febrero de 2015 (recursos n $4432 / 2010$ y 4461/2013), ambas referidas al Ayuntamiento de Fisterra; o las SSTJS de Galicia de 9 de noviembre de 2011 y 27 de junio y 14 de noviembre de 2013 (recursos $\mathrm{n}^{\circ}$ 4292/2010, 4579/2012 y 4342/2013), referidas en todos los casos al Ayuntamiento de Barreiros.

37 STSJ de Cataluña de 26 de septiembre de 2014 (recurso n ${ }^{\circ}$ 129/2013), Ayuntamiento de El Perelló.

38 Rebollo Puig, Manuel (2012): 2028-2029. 
Nada hacía pensar que pudiera producirse un cambio en esta situación, dada la unanimidad de la jurisprudencia, cuando, justamente en Andalucía, la Sala de lo Contencioso del Tribunal Superior de Justicia de Andalucía/Granada, propuso una lectura alternativa de la STS de 29 de septiembre de 2010 (recurso no 12/2009, ponente: Fernández VAlverde) que le permitía negar a la Administración autonómica la legitimación para solicitar la revisión de oficio de los actos nulos adoptados por la Administración local ${ }^{39}$. A partir de esta interpretación alternativa, el Tribunal desarrolla una nueva y original línea jurisprudencial, formada por un copiosísimo número de pronunciamientos, que permanecerá inamovible hasta su final confirmación por parte del Tribunal Supremo.

Salvo error, la primera sentencia de la serie fue la STSJ de Andalucía/Granada de 25 de marzo de 2013 (recurso no 543/2010, ponente: Ruzz Álvarez). En los hechos, casi idénticos a otros casos ya expuestos, la Junta de Andalucía solicitó al Ayuntamiento de Soportújar, pequeño pueblo de poco más de trescientos habitantes de la Alpujarra granadina, la revisión de oficio de una licencia otorgada a la entidad mercantil Carpintería Rodríguez e Hijos, SL, para la construcción de un almacén de madera. El Ayuntamiento de Soportújar acordó inadmitir la solicitud al entender que la Junta de Andalucía no tenía ningún interés directo para ser considerada interesada a fin de instar la revisión de oficio de un acto que no afectaba a la esfera de sus intereses. Interpuesto recurso contencioso-administrativo contra dicha inadmisión por parte de la Junta de Andalucía, este fue parcialmente estimado por el Juzgado de lo Contencioso-Administrativo competente, cuya sentencia fue objeto de un nuevo recurso de apelación, en esta ocasión interpuesto por el Ayuntamiento y que es resuelto por la sentencia que nos ocupa, que estimará la falta de legitimación alegada.

Para justificar la falta de legitimación de la Junta de Andalucía, la sentencia toma como punto de partida, justamente, el mismo precepto del que partía la jurisprudencia elaborada por la Sala de lo Contencioso del Tribunal Superior de Justicia de Andalucía/Málaga y que analizamos más atrás: el art. 190 de la Ley 13/2005, de Ordenación Urbanística de Andalucía, que impone a quien las dictó la obligación de revisar de oficio «las licencias urbanísticas y las órdenes de ejecución, así como cualquier otro acto administrativo previsto en esta Ley, cuyo contenido constituya o habilite de manera manifiesta alguna de las infracciones urbanística graves o muy graves definidas en esta Ley». Eso sí, lejos de entender que este precepto habilita la creación de una vía

39 Para ser precisos, conviene señalar que el origen y desarrollo de esta interpretación alternativa se produce, en concreto, en la Sección Cuarta de la Sala indicada, mientras que otras Secciones de la misma Sala aceptarán, sin tan siquiera cuestionarlo, la legitimación de la Administración autonómica para presentar solicitudes de revisión de oficio contra actos de las Administraciones locales. En este sentido, STSJ de Andalucía/Granada de 25 de marzo de 2013 (recurso n ${ }^{\circ}$ 823/2008), dictada por la Sala Tercera, o STSJ de Andalucía/Granada de 6 de mayo de 2013 (recurso n 543/2010), dictada por la Sala Primera. 
propia para proceder a dicha revisión de oficio, como habían interpretado los demás Tribunales Superiores de Justicia hasta entonces, la sentencia considera, acertadamente, que el artículo obliga a estar a lo regulado en los arts. 102-106 LRJPAC.

Sentado lo anterior, la sentencia entra a analizar si la revisión de oficio «a solicitud de interesado» permite que sea una Administración pública quien la solicite, para lo que acude a la STS de 29 de septiembre de 2010 (recurso n ${ }^{\circ}$ 12/2009, ponente: FERnÁndez VALVERde) donde, como ya vimos, se respondió afirmativamente. Y, finalmente, se atreve a dar el paso que no dio el Tribunal Supremo y entra a discernir si la Administración que solicita la revisión debe ser un «interesado» en sentido jurídico estricto, como parecía exigir el art. 102.1 LRJPAG y exige ahora el art. 106.1 LPAC. La respuesta del Tribunal será rotundamente afirmativa, lo que le permite negar en el caso concreto la legitimación de la Junta de Andalucía, al no ostentar ni un derecho subjetivo ni un interés legítimo sino, más bien, un interés genérico en el ejercicio de sus potestades en materia urbanística:

«En consecuencia, la Administración autonómica no está legitimada, conforme a la anterior doctrina jurisprudencial, para instar, como interesada, de las Administraciones que integran la Administración Local, el inicio del procedimiento de revisión de oficio de los actos administrativos, ya que en esa revisión de oficio 'a solicitud de interesado', a que se refiere el artículo 102.1 de la LRJPAC, no se comprende, pues no está ejercitando derechos o intereses legítimos propios, sino una potestad administrativa, que es más propia de las relaciones interadministrativas que de las relaciones bilaterales con los particulares, según entiende la doctrina científica y la jurisprudencia antes mencionada».

La importancia de este pronunciamiento radica, al menos, en dos elementos: por un lado, supone una ruptura con la unanimidad que hasta entonces había regido entre los pronunciamientos de los Tribunales Superiores de Justicia, que simplemente ignora; por otro lado, lejos de contradecir a la única sentencia del Tribunal Supremo que hasta ese momento se había ocupado de esta materia, la toma como base, asume sus postulados y la completa precisamente allí donde el Alto Tribunal no culminó su labor interpretativa.

A partir de esta primera STSJ de Andalucía/Granada de 25 de marzo de 2013 (recurso no 543/2010, ponente: RuIz Álvarez), se sucederán otras muchas resolviendo exactamente en el mismo sentido, alcanzando hasta la fecha la treintena de pronunciamientos y afectando a un amplio número de municipios distintos ${ }^{40}$. No obstante,

$40 \quad$ STSJ de Andalucía/Granada de 28 de abril de 2014 (recurso n ${ }^{\circ}$ 1785/2009), Ayuntamiento de Armilla; STSJ de Andalucía/Granada de 5 de mayo de 2014 (recurso n ${ }^{\circ}$ 201/2010), Ayuntamiento de Mo- 
entre todas ellas debe destacarse muy especialmente la STSJ de Andalucía/Granada de 28 de abril de 2014 (recurso n ${ }^{\circ}$ 1785/2009; ponente: MuÑoz CORTES), que se sitúa cronológicamente como la segunda sentencia de la serie y en la que se desarrollan y completan, con un admirable rigor, los fundamentos empleados por la primera sentencia, haciendo suyos, por cierto, muchos de los argumentos que hasta ese momento había venido propugnando Rebollo Puig.

Una vez más, el supuesto de hecho del que trae causa esta nueva sentencia viene determinado por la negativa de un Ayuntamiento, en este caso el de Armilla, a admitir la revisión de oficio de una licencia, en este caso concedida para la construcción de un parque comercial, habiendo sido tal revisión solicitada por la Junta de Andalucía varios meses después de que se hubieran agotado los plazos previstos en el art. 65 LRBRL para dirigir el requerimiento potestativo o interponer recurso contencioso-administrativo. Sin perjuicio de otras muy interesantes consideraciones sobre el mecanismo de la revisión de oficio, por cuanto interesa al objeto de este trabajo debemos centrarnos en su extenso Fundamento Jurídico $8^{\circ}$, en el que se analiza la legitimación de la Junta de Andalucía para instar la revisión de oficio de la licencia controvertida, concluyendo que tal legitimación

«no puede sostenerse en base a una mera defensa de la legalidad, sino en relación a la defensa de un derecho o interés legítimo propio, que en el caso de la Administración actuante se podría encontrar en situaciones jurídicas precisas como son la defensa [del] dominio público de su titularidad, [de bienes] patrimoniales o una expropiación concreta, pero no

nachil; SSTJS de Andalucía/Granada de 19 de mayo y 2 de junio de 2014 y 18 de mayo de 2015 (recursos n ${ }^{\circ}$ 593/2011, 954/2013 y 985/2012), Ayuntamiento de La Guardia; STSJ de Andalucía/Granada de 9 de junio de 2014 (recurso no 1030/2003), Ayuntamiento de Mojácar; STSJ de Andalucía/Granada de 29 de septiembre de 2014 (recurso n ${ }^{\circ}$ 498/2011), Ayuntamiento de Peligros; STJS de Andalucía/Granada de 16 de febrero de 2015 (recurso n 2064/2008), Ayuntamiento de Nívar; SSTJS de Andalucía/Granada de 2 de septiembre y 17 de noviembre de 2014, 2 de febrero, 1 de junio, 20 de julio y 26 de octubre de 2015 y 26 de febrero de 2016 (recursos n ${ }^{\circ}$ 1835/2007, 2068/2008, 1054/2008, 1467/2010, 213/2013, 599/2012 y 56/2015), Ayuntamiento de Almuñécar; STJS de Andalucía/Granada de 22 de junio de 2015 (recurso n 697/2013), Ayuntamiento de Roquetas de Mar; SSTJS de Andalucía/Granada de 9 de marzo y 4 de mayo de 2015 (recursos no 79/2010 y 249/2012), Ayuntamiento de Zurgena; STJS de Andalucía/Granada de 9 de febrero y de 6 de abril de 2015 (recursos n ${ }^{\circ}$ 1814/2008 y 1407/2010), Ayuntamiento de Cuevas de Almanzora; STJS de Andalucía/Granada de 20 de octubre de 2014 (recurso n ${ }^{\circ}$ 885/2008), Ayuntamiento de Partaloa; STJS de Andalucía/Granada de 13 de julio de 2015 (recurso n ${ }^{\circ}$ 285/2013), Ayuntamiento de Cadiar; STJS de Andalucía/Granada de 20 de abril de 2015 (recurso n 1207/2010), Ayuntamiento de Carataunas; STJS de Andalucía/Granada de 30 de marzo de 2015 (recurso no 957/2010), Ayuntamiento de Íllora; STJS de Andalucía/Granada de 14 de diciembre de 2015 (recurso n ${ }^{\circ}$ 424/2014), Ayuntamiento de Adra; SSTJS de Andalucía/Granada de 11 y 18 de mayo de 2015 (recursos n 828/2012 y 1118/2012), Ayuntamiento de Cantoria; STJS de Andalucía/Granada de 14 de marzo de 2016 (recurso no 229/2015), Ayuntamiento de Fines. 
en las competencias atribuidas para el control de la legalidad como puede ser la inspección urbanística. Y es que no cabe olvidar que para el ejercicio de unas facultades de control de la legalidad, la Junta de Andalucía cuenta con los mecanismos específicos previstos en la Ley de Bases de Régimen Local, que no ha ejercitado pese a disponer de ocasión para ello».

Es decir, la STSJ de Andalucía/Granada de 28 de abril de 2014 (recurso n $^{\circ}$ 1785/2009; ponente: MuÑoz CORTES) admite, como ya habían hecho su predecesora inmediata y el propio Tribunal Supremo, la posibilidad de que las Administraciones superiores puedan solicitar la revisión de oficio de los actos dictados por las Administraciones locales al amparo del art. 102.1 LRJPAC. Pero, eso sí, solo cuando se encuentren directamente afectadas por tales actos y no como meras defensoras de la legalidad. La legitimación como simple defensoras de la legalidad resultaría también admisible, ciertamente, pero solo dentro de los estrictos términos del art. 65 LRBRL, pues «el concepto de interesado no ampara la inclusión de la mera defensa de la legalidad efectuada por la Administración competente en una materia, si no es en la medida y por el procedimiento que una disposición de carácter legal así lo ha establecido, tal y como ocurre en el art 65 de la LBRL». En consecuencia, una vez transcurridos los plazos preclusivos establecidos en este último artículo, el acto deviene inimpugnable, tanto por esta vía, como por la vía de la revisión de oficio ${ }^{41}$.

Como colofón a sus razonamientos, y en línea con lo que ya había adelantado la doctrina, la sentencia también destaca las catastróficas consecuencias de la interpretación contraria (que, de hecho, habían comenzado a producirse a partir de la aparición de la STS de 29 de septiembre de 2010 ${ }^{42}$. En efecto, «reconocer legitimación en el referido procedimiento [de revisión de oficio] a la Administración autonómica en base a la mera defensa de la legalidad supon[dría] minimizar de forma absoluta el papel de la LRBRL en la regulación de las relaciones entre administraciones Local, Estatal y Autonómica, cuando de actos presuntamente nulos se tratase, pues fácilmente cabe pensar que nadie acudirá a los preclusivos plazos contemplados en aquella cuando mantenga abierta la generosa posibilidad del procedimiento de revisión de oficio». A lo que habría que sumar la inseguridad jurídica que generaría el aceptar que cualquier Administración, en cualquier momento, aun sin tener interés afectado alguno, pudiera solicitar la revisión de oficio de los actos dictados por una Administración distinta.

${ }^{41}$ En un encomiable ejercicio de previsión, la sentencia deja al margen de esta afirmación, sin embargo, un supuesto: «la eventual legitimación para instar la revisión de oficio en ausencia de un derecho o interés legítimo afectado, respecto a aquellos vicios de nulidad que pudieran hacerse presentes después de haber precluido el plazo de ejercicio de las facultades de control de la LBRL y que, por tanto, no hubieran permitido en su momento el ejercicio de los mismos».

42 Nuevamente, Rebollo Puig, Manuel (2010): 458-459 y Rebollo Puig, Manuel (2012): 20282033. 


\section{EL DEFINITIVO RECHAZO DEL TRIBUNAL SUPREMO A LA LEGITIMAGIÓN DE LA ADMINISTRACIÓN AUTONÓMICA PARA SOLICITAR LA REVISIÓN DE OFICIO}

Como era previsible, esta nueva línea jurisprudencial fue impugnada por la Junta de Andalucía ante el Tribunal Supremo, lo que resultaba plenamente razonable si se atiende a que estos pronunciamientos se separaban de lo sostenido hasta ese momento por todos los Tribunales Superiores de Justicia que se habían ocupado del tema (incluyendo al propio Tribunal Superior de Justicia de Andalucía/Málaga) y a que el Tribunal Supremo había mantenido una postura, cuando menos, ambigua, en la STS de 29 de septiembre de 2010. De esta forma, acabó dictándose la STS de 12 de abril de 2016 (recurso no 3550/2014, ponente: DE Oro-Pulido López), en la que el Alto Tribunal, como ya adelantamos, aclara definitivamente su postura en esta controversia, aceptando como propia la interpretación propugnada por el TSJ de Andalucía/ Granada. Esto es, se niega la legitimación general de la Administración autonómica para solicitar la revisión de oficio de actos nulos adoptados por las Administraciones locales que no fueron impugnados en su momento por las vías del art. 65 LRBRL.

La sentencia viene a resolver el recurso de casación interpuesto contra la STSJ de Andalucía/Granada de 9 de junio de 2014 (recurso n ${ }^{\circ}$ 1030/2003), en la que, nuevamente, se negó la legitimación de la Junta de Andalucía para solicitar la revisión de oficio de unos acuerdos adoptados en materia urbanística por el Ayuntamiento de Mojácar ${ }^{43}$. Con el fin de fijar los términos del debate, el Tribunal Supremo confirma, en primer lugar, que el concepto de interesado al que se refería el art. 102.1 LRJPAC era el concepto de interesado ofrecido por el art. 31.1 LRJPAC. Un concepto que

«en líneas generales, se corresponde con el portador de derechos e intereses legítimos, más no de potestades administrativas (...), [pues] están legitimados para instar el procedimiento especial de revisión de oficio de los actos administrativos regulado en el artículo 102 de la Ley 30/1992 (...) los titulares de derechos o intereses legítimos que dimanan del acto cuya nulidad de pleno derecho se pretende, en cuanto que de dicha declaración de nulidad radical se produzca un beneficio o efecto favorable completo, cierto y directo para el accionante, sin que baste el mero interés de defensa de la legalidad».

43 La naturaleza de uno de los acuerdos adoptados era la de norma reglamentaria (aprobación definitiva de un estudio de detalle), lo que permite al Tribunal Supremo, en relación con este concreto acuerdo, limitarse a negar la legitimación de la Junta de Andalucía señalando, simplemente, que el art. 102.2 LRJPAC no contemplaba que la revisión de oficio de las disposiciones administrativas pudiera iniciarse a solicitud de interesado. A tal fin, el Tribunal Supremo no deja pasar la oportunidad de remitirse a su relativamente reciente STS de 21 de mayo de 2015 (recurso n ${ }^{\circ}$ 3004/2012, ponente: DE Oro-Pulido López) en la que, según vimos, despejó definitivamente las ambigüedades que se habían introducido sobre este punto en su jurisprudencia como resultado de la equívoca STS de 29 de septiembre de 2010. 
La sentencia constata que, en este caso, la Junta de Andalucía no estaba ejercitando derechos o intereses legítimos propios, puesto que la anulación del acto no le hubiera generado ningún beneficio o efecto favorable concreto. En su lugar, estaba ejercitando una potestad administrativa, concretamente la de exigir al Ayuntamiento que actuara de acuerdo con la legalidad. En consecuencia, y «no habiendo, pues, supuesto el tan citado artículo 102.1 ampliación de la regulación contenida en la Ley de Bases de Régimen Local», la Junta de Andalucía quedaba obligada a acudir al art. 65 LRBRL para impugnar los actos y acuerdos de las Entidades Locales que incurrieran en infracción del ordenamiento jurídico en los plazos y formas allí establecidos. Al no hacerlo así, «dejando precluir los plazos previstos al efecto (...) tal omisión no puede ser suplida por dicha Administración acudiendo inadecuadamente a la vía de revisión de oficio».

\section{CONCLUSIÓN: LA DEGRADACIÓN DE LA ADMINISTRACIÓN AUTONÓMICA A LA POSICIÓN DE MERA DENUNGIANTE Y SUS NADA DESDEÑABLES CONSEGUENGIAS}

Con la STS de 12 de abril de 2016 (recurso no 3550/2014, ponente: DE Oro-PuLIDO LÓPEZ) puede darse definitivamente por cerrada la controversia acerca de la legitimación de la Administración autonómica para solicitar la revisión de oficio de los actos dictados por la Administración local. La situación resultante puede resumirse, en síntesis, del siguiente modo:

- cuando la Administración autonómica (o la estatal) pretendan impugnar un acto adoptado por una Entidad local en el ejercicio de sus funciones genéricas de control de la legalidad de la actuaciones locales, deberán acudir, necesariamente, a las vías que ofrece el art. $65 \mathrm{LRBRL}$; una vez transcurridos los plazos preclusivos establecidos en dicho artículo, el acto devendrá inimpugnable;

- con independencia de lo anterior, la Administración autonómica (y la estatal) puede acudir a la vía del art. 106.1 LPAC y solicitar, en cualquier tiempo, la revisión de oficio de los actos nulos de pleno derecho adoptados por la Administración local; no obstante, dicha posibilidad queda restringida a aquellos supuestos en los que la Administración autonómica pueda considerarse «interesada» en el sentido del art. 4 LPAC, esto es, cuando ostente un verdadero derecho subjetivo o, al menos, un interés legítimo, no siendo suficiente el simple interés o el mero deseo de ejercer las potestades de control de la legalidad que le han sido atribuidas por el ordenamiento y que no fue capaz de ejercer en su momento.

La principal consecuencia de lo expuesto es que la Administración autonómica no puede continuar haciendo el uso indiscriminado de la «acción de nulidad» reco- 
gida en el art. 106.1 LPAC que venía desplegando contra los actos de las Entidades locales y que los tribunales le habían permitido realizar hasta ahora. Es decir, la Administración autonómica no tiene derecho a que la Administración local autora de un acto nulo inicie y tramite un procedimiento de revisión de oficio contra dicho acto, puesto que ese derecho se reserva a los «interesados» en sentido estricto, únicos titulares de la indicada «acción de nulidad» ${ }^{44}$.

Ahora bien, que la Administración autonómica no pueda ejercer una verdadera «acción de nulidad» en estos supuestos, no significa que no pueda desplegar actuación alguna. En efecto, en todo caso y como mínimo la Administración autonómica podrá denunciar la nulidad del acto ante la Administración local autora del mismo, invitándola, instándola o requiriéndola para que proceda a su revisión de oficio. En tanto que mera denuncia, esta actuación no generará las mismas obligaciones para la Administración local que las que genera la presentación de una verdadera «acción de nulidad» por parte de un verdadero interesado y amparada en el art. 106.1 LPAC. Pero, aunque menores, tales obligaciones existen.

Debe tenerse en cuenta que la revisión de oficio de los actos administrativos se configura como una potestad reglada ${ }^{45}$. Este carácter reglado de la potestad, según se ha entendido tradicionalmente, sería una exigencia del principio de legalidad: dado que la actuación administrativa se somete plenamente, por mandato constitucional y sin excepción, a la Ley y al Derecho (art. 103.1 GE) y dada la imposibilidad de convalidar los actos nulos de pleno derecho (cfr. art. 52.1 LPAG), si la Administración tiene conocimiento de la existencia de un acto aquejado de alguno de los vicios previstos en el art. 47.1 LPAC, debe declararlo expresamente. O, para ser más exactos, y atendiendo a que pueden concurrir límites a la declaración de nulidad (art. 110 LPAC), tiene la obligación de iniciar el oportuno procedimiento de revisión, en cuyo seno se determinará si procede o no dicha declaración.

Ahora bien, esta obligación conlleva importantes consecuencias, conocidas también en otros ámbitos de la actividad administrativa, puesto que suponen el reconocimiento de una importante posición al denunciante de la posible nulidad del acto

44 Sobre el ejercicio y el contenido de la «acción de nulidad» que ostentan los interesados y el alcance de su control por los órganos de lo contencioso-administrativo, que en esta fase se limitan a garantizar el «derecho a la tramitación», pero no el «derecho a la declaración de nulidad», Bueno Armijo, Antonio (2016): 393-396.

$45 \mathrm{El}$ art. 106.1 LPAC mantiene la literalidad del anterior art. 102.1 LRJPAC introducida por la Ley 4/1999, que sustituyó el verbo «podrán» por «declararán», como había reclamado la doctrina. José Ramón PARAda VÁzQuez, «La revisión de oficio», en fornadas de Estudio sobre la Reforma de la Ley 30/1992: Fornadas celebradas en Sevilla los días 23 y 24 de febrero de 1997, Ministerio de Administraciones Públicas - BOE, 1997, Madrid, p. 139. Cfr., sin embargo, con el art. 217.1 LGT que mantiene la expresión «podrá declararse la nulidad de pleno derecho $(\ldots) »$. 
administrativo. En efecto, cualquier denunciante, aunque no pueda ser considerado interesado ni participar, en consecuencia, en el procedimiento, estaría poniendo a la Administración en el brete de tener que actuar en cuanto aportase a esta la información necesaria para considerar que un acto es o pudiera ser nulo ${ }^{46}$. Incluso si dicho denunciante es otra Administración pública.

Y algo muy similar ocurriría respecto a la revisión de oficio de disposiciones administrativas (art. 106.2 LPAG). En efecto, que el procedimiento de revisión de oficio contra reglamentos no pueda iniciarse a solicitud de interesado, según hemos expuesto en epígrafes anteriores, no obsta a que los particulares u otra Administración puedan presentar denuncia, en el sentido técnico jurídico apuntado ahora por el art. 62 LPAC de «pone $[\mathrm{r}]$ en conocimiento de un órgano administrativo la existencia de un determinado hecho que pudiera justificar la iniciación de oficio de un procedimiento administrativo». Es decir, dado que la Administración está obligada a la revisión de oficio de sus actos o disposiciones nulas, cualquier ciudadano u otra Administración, aun sin contar con un derecho subjetivo o un interés legítimo, podrían dirigirle un requerimiento para que pusiera en marcha el proceso de revisión ${ }^{47}$.

De este modo, aun cuando no sea posible reconocer al denunciante un derecho a obtener un pronunciamiento anulatorio, sí que podría sostenerse que tiene derecho al menos: a recibir acuse de recibo de la Administración a la que ha dirigido su denuncia; a que esta inicie, al menos, los trámites necesarios para determinar si existen indicios de la invalidez denunciada; y a ser informado del resultado de dichos trámites ${ }^{48}$. Por supuesto, la negativa de la Administración a incoar el procedimiento

46 A estos efectos, resultaría irrelevante la inexistencia de un interés legítimo en la declaración de nulidad del acto porque la revisión de oficio «no responde a ningún otro interés fuera del propio del ordenamiento jurídico: la declaración de nulidad se efectúa en el interés objetivo del ordenamiento; se trata de un interés in re ipsa», Raúl Bocanegra Sierra, La revisión de oficio de los actos administrativos, Instituto de Estudios de la Administración Local, Madrid, 1977, p. 236.

47 Esta posición ha sido tradicionalmente defendida, en relación con las normas reglamentarias, por Eduardo García de Enterría y Tomás Ramón Fernández, Curso de Derecho Administrativo. I, Civitas, $11^{\text {a }}$ edición, 2002, Madrid, p. 227: «reconocida la nulidad absoluta del reglamento inconstitucional o ilegal, queda reconocida también necesariamente, y sin necesidad de texto legal expreso que lo ratifique, la obligación de la Administración de eliminar dicho reglamento desde el momento mismo que advierta la inconstitucionalidad o ilegalidad del mismo, bien por su propia reflexión al respecto, o bien en virtud de la denuncia que (...) pueda formular ante ella cualquier persona, cuya solicitud al respecto constituirá a la Administración que la recibe en el inexcusable deber de pronunciarse al respecto, ya que en modo alguno puede considerarse dicha solicitud como una petición meramente graciable». En el mismo sentido, más recientemente, Suay García, José (2014): 1393.

48 Los particulares podrían, incluso, ejercer su genérico derecho de petición, de acuerdo con la regulación contenida en los arts. 2 y 3 LO 4/2001, de 12 de noviembre, Reguladora del Derecho de Petición (LODP). Esta posibilidad, sin embargo, no parece que esté abierta a las Administraciones públicas. Es cierto que el art. 1 LODP reconoce el derecho de petición a «toda persona, natural o jurídica, prescindiendo de su nacionalidad», lo que amplía notablemente el ámbito subjetivo que se había dado a este derecho en el art. 
no podrá ser objeto de control jurisdiccional. Pero sí lo podría ser la inactividad de la Administración ante la existencia de indicios denunciados por un ciudadano (u otra Administración), para decidir si debe o no incoarse dicho procedimiento.

29 CE («todos los españoles tendrán el derecho de petición»). Aun así, es muy dudoso que las Administraciones públicas puedan considerarse titulares de un derecho que podría ejercerse ante cualquier institución pública, incluyendo cámaras legislativas o miembros del poder judicial. 